\title{
Satellite observations of peroxyacetyl nitrate from the Aura Tropospheric Emission Spectrometer
}

\author{
V. H. Payne ${ }^{1}$, M. J. Alvarado ${ }^{2}$, K. E. Cady-Pereira ${ }^{2}$, J. R. Worden ${ }^{1}$, S. S. Kulawik ${ }^{3}$, and E. V. Fischer ${ }^{4}$ \\ ${ }^{1}$ Jet Propulsion Laboratory, California Institute of Technology, Pasadena, California, USA \\ ${ }^{2}$ Atmospheric and Environmental Research, Lexington, Massachusetts, USA \\ ${ }^{3}$ Bay Area Environmental Research Institute, Mountain View, California, USA \\ ${ }^{4}$ Colorado State University, Fort Collins, Colorado, USA \\ Correspondence to: V. H. Payne (vivienne.h.payne@jpl.nasa.gov)
}

Received: 7 May 2014 - Published in Atmos. Meas. Tech. Discuss.: 3 June 2014

Revised: 1 October 2014 - Accepted: 2 October 2014 - Published: 12 November 2014

\begin{abstract}
We present a description of the algorithm used to retrieve peroxyacetyl nitrate (PAN) concentrations from the Aura Tropospheric Emission Spectrometer (TES). We describe the spectral microwindows, error analysis, and the utilization of a priori and initial guess information provided by the GEOS-Chem global chemical transport model. The TES PAN retrievals contain up to one degree of freedom for signal. In general, the retrievals are most sensitive to PAN in the mid-troposphere. Estimated single-measurement uncertainties are on the order of 30 to $50 \%$. The detection limit for a single TES measurement is dependent on the atmospheric and surface conditions as well as on the instrument noise. For observations where the cloud optical depth is less than 0.5 , we find that the TES detection limit for PAN is in the region of 200 to 300 pptv. We show that PAN retrievals capture plumes associated with boreal burning. Retrievals over the Northern Hemisphere Pacific in springtime show spatial features that are qualitatively consistent with the expected distribution of PAN in outflow of Asian pollution.
\end{abstract}

\section{Introduction}

Peroxyacetyl nitrate (PAN) is a thermally unstable reservoir for active nitrogen $\left(\mathrm{NO}_{\mathrm{x}}\right)$ that allows for $\mathrm{NO}_{\mathrm{x}}$ to be transported over large distances, enabling efficient ozone formation far downwind from the original source (Singh and Hanst, 1981; Hudman et al., 2004; Fischer et al., 2010; Singh, 1987). The dissociative lifetime of PAN is strongly dependent on air mass temperature, being longer than 1 month at temperatures characteristic of the mid-troposphere, but only on the order of $1 \mathrm{~h}$ at $20 \mathrm{C}$. The stability of PAN at midtropospheric temperatures allows for the compound to be transported on a hemispheric scale. PAN therefore plays a fundamental role in the long-range transport of $\mathrm{NO}_{\mathrm{x}}$ and in the global $\mathrm{O}_{3}$ budget.

Existing aircraft and surface observations show that PAN is present in the atmosphere at mixing ratios ranging from a few pptv in the remote marine atmosphere to several ppbv in polluted urban environments and biomass burning plumes (e.g., Singh and Salas, 1986; Ridley et al., 1990; Singh et al., 1990, 1998; Fischer et al., 2010). However, aircraft and surface measurements of PAN have primarily been campaignbased and therefore limited in spatial and temporal coverage (Fischer et al., 2014, and references therein). The existing suite of in situ observations provides only snapshots of the global atmospheric PAN distribution. Given the very limited set of long-term measurements, there are gaps in our knowledge of the distribution, seasonal cycle and interannual variability of PAN, and the processes driving these features.

Satellite observations provide opportunities to collect information on a global scale, over multiyear timescales. PAN is readily detectable via satellite remote sensing in the thermal infrared region. PAN has previously been retrieved in the upper troposphere and lower stratosphere from limb observations on a global scale from the Envisat Michelson Interferometer for Passive Atmospheric Sounding (MIPAS) (Moore and Remedios, 2010; Wiegele et al., 2012) and from the Canadian Atmospheric Chemistry Experiment Fourier Transform Spectrometer (ACE-FTS) (Tereszchuk et 


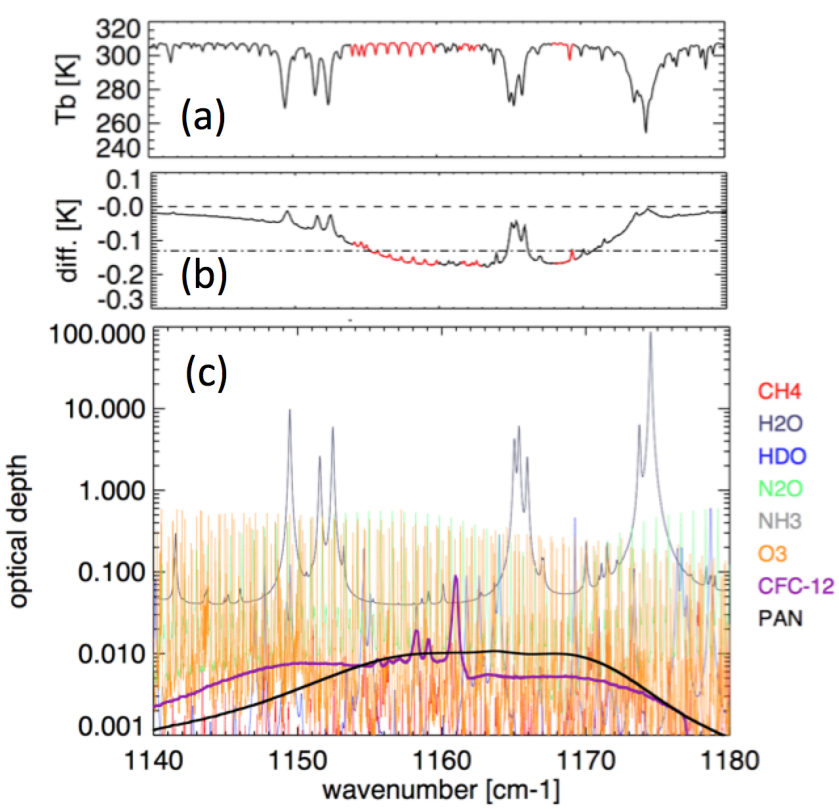

Figure 1. (a) Simulated TES spectrum in the PAN spectral region. Red regions show the spectral regions utilized in the TES PAN retrievals. (b) Brightness temperature difference for simulations with and without PAN for the two PAN profiles shown in Fig. 2. (The signal for these two profiles cannot be distinguished by eye.) Dotted line shows the TES noise for a single observation. (c) Optical depth contributions for the dominant interfering species in this spectral region. Species other than PAN are for a US standard atmosphere.

al., 2013). PAN signatures have also been observed in nadir observations of smoke plumes from fires by both the Aura Tropospheric Emission Spectrometer (TES) (Alvarado et al., 2011) and MetOp-A Infrared Atmospheric Sounding Instrument (IASI) (Clarisse et al., 2011), but, to our knowledge, PAN has not previously been retrieved in the nadir view on a global scale.

Building on the detection of PAN in TES radiances described by Alvarado et al. (2011), we have developed a PAN retrieval product for TES. Here we describe the algorithm and the product. In Sect. 2, we provide background on the TES instrument, including information on temporal and spatial sampling. In Sect. 3, we describe the TES PAN retrieval, and in Sect. 4 we show initial results for the northern Pacific in April 2008.

\section{TES measurements}

The Aura TES instrument, a nadir-viewing Fourier transform spectrometer measuring thermal-infrared radiances with extremely high spectral resolution $\left(0.06 \mathrm{~cm}^{-1}\right)$, provides information on a large number of different trace gases, including PAN.

The TES instrument uses a 16-element detector array. The total surface footprint is $8 \mathrm{~km}$ by $5 \mathrm{~km}$ at nadir $(0.5 \mathrm{~km}$ by
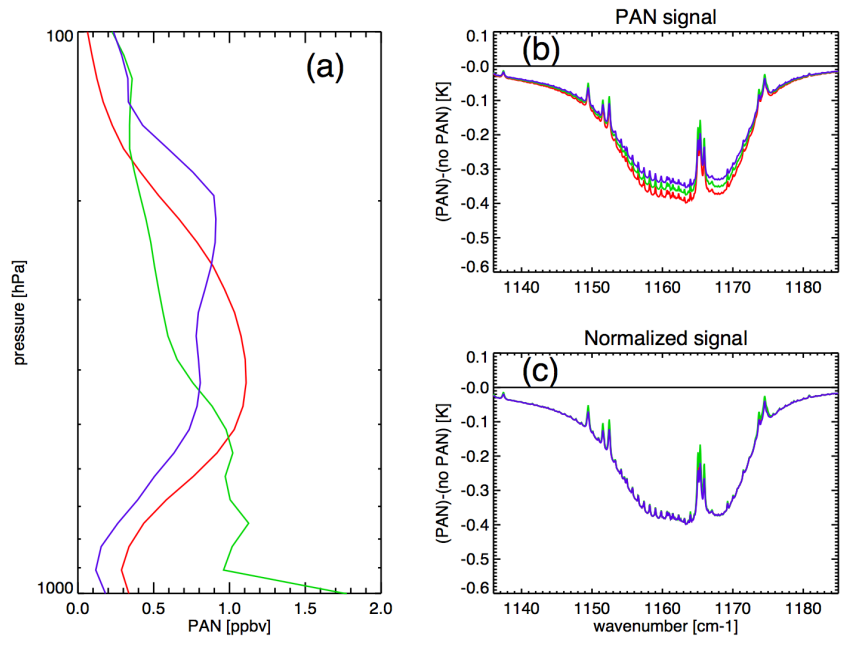

Figure 2. (a) Three highly elevated PAN profiles, each with different vertical structure. (b) Brightness temperature signals resulting from the three elevated profiles. (c) is the same as (b) but with each of the signals normalized to the greatest brightness temperature difference value shown in (b).

$5 \mathrm{~km}$ footprint for each detector). The nominal mode of the instrument is "global survey" mode, where TES makes periodic measurements every $\sim 200 \mathrm{~km}$ along the satellite track. Other measurement modes are step-and-stare mode and transect mode. In step-and-stare mode, nadir measurements are made every $40 \mathrm{~km}$ along the track for a specified latitude range. In transect mode, a series of 40 consecutive scans spaced $12 \mathrm{~km}$ apart is performed, providing relatively dense coverage over a limited area.

Figure 1 shows a simulated TES spectrum, alongside the PAN signature (difference between simulations with and without PAN) for a PAN profile with a peak value of 0.4 ppbv. Figure 1 also shows the optical depth contributions from PAN and other molecules with signatures in this spectral region. It can be seen that there is strong interference in this region from water vapor $\left(\mathrm{H}_{2} \mathrm{O}\right)$, deuterated water vapor (HDO), ozone $\left(\mathrm{O}_{3}\right)$, nitrous oxide $\left(\mathrm{N}_{2} \mathrm{O}\right)$ and $\mathrm{CFC}-12$. Additional interfering species in this region (not shown in Fig. 1) include HFC-23, HCFC-141b, CFC-113, HFC-134a, HCFC-22, CFC-114, CFC-115, HFC-152a and HFC-125. However, these molecules have very weak signatures compared to PAN.

The same magnitude of PAN signal in TES measurements can result from different PAN profiles. The shape of the PAN signal is not sensitive to the details of the vertical structure of the PAN profile. Figure 2 shows three highly elevated PAN profiles, each with different vertical structure, alongside their associated brightness temperature signals. Also shown are the signals normalized to the maximum strongest signal of the three cases, in order to demonstrate, although the shapes of the profiles are different, that the spectral shape of the resulting signal as seen by TES is the same. 
Other bands of PAN are located at around 800, 1300, 1730 and $1840 \mathrm{~cm}^{-1}$. TES retrievals at $800 \mathrm{~cm}^{-1}$ are not possible due to higher instrument noise in the TES $650-900 \mathrm{~cm}^{-1}$ range. The PAN feature at $1300 \mathrm{~cm}^{-1}$ is strongly impacted by interference from methane and water vapor, which overwhelm the PAN signal. The 1730 and $1840 \mathrm{~cm}^{-1}$ PAN absorption bands are outside the spectral ranges measured by TES. These bands, although covered by other spaceborne thermal infrared instruments, are very strongly impacted by water vapor interference, which would complicate their use in retrievals.

\section{PAN retrievals}

\subsection{Forward model}

The forward-model component of the TES operational retrieval is described in detail in Clough et al. (2006). The TES forward model is based on the Line-By-Line Radiative Transfer Model (LBLRTM) (Clough et al., 2005; Alvarado et al., 2012). The required inputs include the temperature profile, profiles for relevant molecular species, cloud and aerosol characteristics, and the parameters necessary to describe the radiative properties of the surface.

The spectroscopic input used here for PAN are the crosssection data from the HITRAN 2008 compilation (Rothman et al., 2009), which were in turn taken from the work of Allen et al. $(2005 \mathrm{a}, \mathrm{b})$.

\subsection{Retrieval approach}

The TES PAN retrieval uses an optimal estimation approach (Rodgers, 2000; Bowman et al., 2006). Provided that the retrieved state is close to the true state, the retrieved state can be expressed as

$\hat{\boldsymbol{x}}_{\mathrm{a}}=\boldsymbol{x}_{\mathrm{a}}+\mathbf{A}\left(\boldsymbol{x}-\boldsymbol{x}_{\mathrm{a}}\right)+\mathbf{G} \boldsymbol{n}+\mathbf{G K}_{b}\left(\boldsymbol{b}-\boldsymbol{b}_{\mathrm{a}}\right)+\mathbf{G} \Delta \boldsymbol{f}$,

where $\hat{\boldsymbol{x}}, \boldsymbol{x}_{\mathrm{a}}$ and $\boldsymbol{x}$ are the retrieved, a priori and "true" state vectors. The state vectors are expressed as the natural logarithm of volume mixing ratio (VMR) for TES trace gas retrievals. The gain matrix, $\mathbf{G}$, maps from radiance space into profile space. The vector $\boldsymbol{n}$ is the noise on the spectral radiances. The vector $\boldsymbol{b}$ represents the true state for parameters that affect the modeled radiance but are not included in the retrieval state vector (such as calibration, concentrations of interfering gases, etc.). The vector $\boldsymbol{b}_{\mathrm{a}}$ holds the corresponding a priori values. The Jacobian, $\mathbf{K}_{b}=\partial \mathbf{L} / \partial \boldsymbol{b}$, describes the sensitivity of the forward-modeled radiances $\mathbf{L}$ to the vector b. The vector $\Delta f$ represents the error in the forward model relative to the true physics. Spectroscopic errors would be one component of the forward-model error.

The averaging kernel, $\mathbf{A}$, describes the sensitivity of the retrieved state to the true state:

$\mathbf{A}=\frac{\partial \hat{\boldsymbol{x}}}{\partial \boldsymbol{x}}=\left(\mathbf{K}^{\mathbf{T}} \mathbf{S}_{n}^{-1} \mathbf{K}+\mathbf{R}\right)^{-1} \mathbf{K}^{\mathbf{T}} \mathbf{S}_{n}^{-1} \mathbf{K}=\mathbf{G K}$.
Table 1. Microwindows used in the TES PAN retrieval (and preceding emissivity retrieval step).

\begin{tabular}{ll}
\hline Target of retrieval & Wave number ranges $\left[\mathrm{cm}^{-1}\right]$ \\
\hline Surface emissivity & $1142.98-1145.98,1178.98-1180.00$ \\
\hline PAN & $1154.02-1160.02,1161.52-1163.02$, \\
& $1168.00-1169.62$ \\
\hline
\end{tabular}

Here, $\mathbf{K}$ is the sensitivity of the forward-modeled radiances to the state vector $(\mathbf{K}=\partial \mathbf{L} / \partial \hat{\boldsymbol{x}})$. The noise covariance matrix, $\mathbf{S}_{n}$, represents the noise in the measured radiances. $\mathbf{R}$ is the constraint matrix for the retrieval.

For profile retrievals, the widths of the rows of A provide a measure of the vertical resolution of the retrieval. Provided that the retrieval is sufficiently linear, the sum of each row of A indicates the fraction of retrieval information that comes from the measurement as opposed to the a priori at a given altitude (Rodgers, 2000). ("Sufficiently linear" means that, although the retrieval problem itself is nonlinear (and requires iteration to reach a solution), a linearization about some prior state is adequate to find a solution.) The trace of the averaging kernel matrix gives the number of degrees of freedom for signal (DOFS), or independent pieces of information, for the retrieval.

The PAN retrievals are carried out after the retrievals of temperature, water vapor, ozone, carbon dioxide, methane, nitrous oxide, deuterated water vapor, cloud optical depth, cloud height, and surface temperature and emissivity. For these quantities, we use the output from the v05 TES level 2 algorithm as input to the initial step for the PAN retrieval process. (TES level 2 products are publicly available from the Langley Research Center's Atmospheric Science Data Center - see http://asdc.larc.nasa.gov/search/tes/).

Previous retrieval steps do not utilize the spectral regions immediately adjacent to the PAN feature. We choose to re-fit for surface emissivity using spectral windows located on either side of the PAN absorption feature before attempting the retrieval of PAN itself. This provides a baseline for the additional absorption from PAN. We then assume that the surface emissivity varies linearly across the PAN spectral region. The microwindows used for the emissivity and PAN retrieval steps are shown in Table 1.

As stated above, the retrieval minimizes differences between observed and calculated radiances. The difference between observed and calculated radiances can be expressed as the measurement $\left(\chi_{\text {measurement }}^{2}\right)$ component of the cost function

$\chi_{\text {measurement }}^{2}=(\boldsymbol{y}-\mathbf{F}(\hat{\boldsymbol{x}}))^{\mathbf{T}} \mathbf{S}_{n}^{-1}(\boldsymbol{y}-\mathbf{F}(\hat{\boldsymbol{x}}))$,

A $\chi_{\text {measurement }}^{2}$ value equal to 1.0 indicates that the radiances are fit within the expected noise. Since the PAN signal is generally relatively weak compared to the noise on the TES radiances, we find that there are incidences where the residuals 


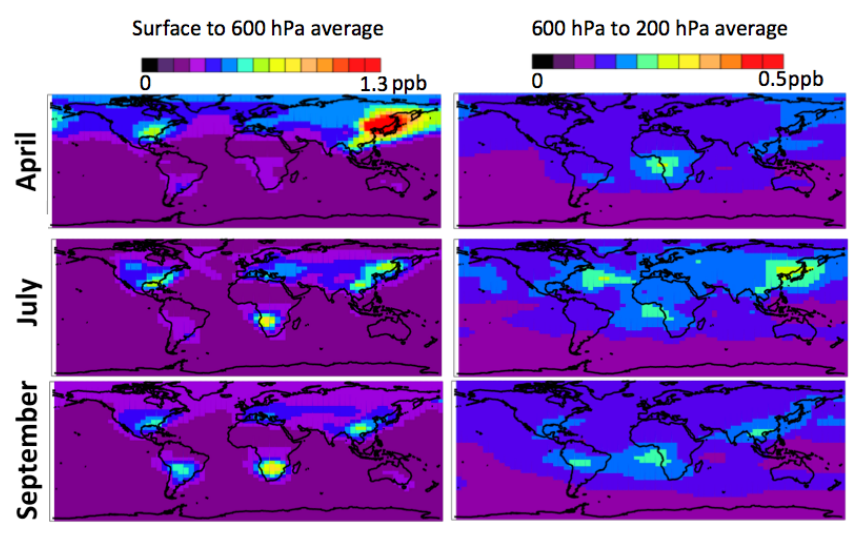

Figure 3. PAN fields from GEOS-Chem. Panels on left show average PAN VMR between $600 \mathrm{hPa}$ and surface for April (top), July (middle) and September (bottom) 2008. Panels on right show averaged VMR between 600 and $200 \mathrm{hPa}$.

at the point of the PAN initial step show features that would overwhelm the PAN signal, making a PAN retrieval unfeasible. (This will be discussed in more detail in Sect. 3.6.) Therefore, we choose not to attempt PAN retrievals for cases where the $\chi_{\text {measurement }}^{2}$ value at the initial PAN step is greater than 3.0. The value of 3.0 was determined empirically.

\subsection{A priori constraints}

We have chosen to use a monthly varying prior constraint for the TES PAN retrievals, based on information from state-ofthe-science simulations from the GEOS-Chem global chemical transport model. The GEOS-Chem PAN simulations as used here are described in detail in Fischer et al. (2013). The model is broadly consistent with existing surface and aircraft observations, which in themselves do not provide sufficient coverage from which to build a climatology. Existing observations lead us to expect certain features in the global distribution of PAN. Figure 3 shows GEOS-Chem PAN distributions for April, July and September 2008. This figure shows three main features of the global distribution: a springtime surface maximum in PAN in the Northern Hemisphere, a maximum aloft in Northern Hemisphere in summer, and a maximum aloft in the tropical South Atlantic in the austral spring. Starting from a monthly mean GEOS-Chem simulation on a $4^{\circ}$ latitude by $5^{\circ}$ longitude grid, we created six a priori profiles for each month, using the following approach. First, we categorized all model profiles into tropical regions $\left(18^{\circ} \mathrm{S}\right.$ to $\left.18^{\circ} \mathrm{N}\right)$ and regions outside the tropics in order to account for the variation in the tropopause with latitude. Profiles were classified as clean if the maximum concentration within the profile was less than $0.3 \mathrm{ppbv}$, and enhanced otherwise. Enhanced profiles were further classified according to whether the maximum PAN value occurred at a pressure higher than $600 \mathrm{hPa}$ (surface maximum) or at a pressure less than $600 \mathrm{hPa}$ (maximum aloft). For each of these six cate- gories, all available model profiles falling into the relevant category were averaged. The a priori profiles for the month of July are shown in Fig. 4 as an example. Since little information exists about variations in the global distribution of PAN from one year to the next, we use the same a priori profiles for all years of TES data.

For each model grid box, we classify the model profile in that grid box according to one of the six categories described above and use the relevant average profile for that category as the retrieval a priori. At the start of the retrieval, the observation coordinates and month are used to select the relevant a priori profile. The initial guess for each retrieval is always set to a profile with a uniform value of $0.3 \mathrm{ppbv}$ in the troposphere. (The stratospheric values follow the GEOS-Chem profiles, which drop off rapidly above the tropopause.) The initial guess is set to a moderately high value in order to start at a moderately sized Jacobian that allows for the retrieval to move either higher or lower, rather than starting at a smaller value which results in a smaller Jacobian that can either jump beyond the true state or get stuck at the initial guess depending on other retrieved parameters. (If the initial guess is set too small, then we can enter a space where the Jacobians are effectively zero. This is a particular issue for $\log (\mathrm{vmr})$ retrievals, since the Jacobians are state-dependent. If the Jacobians are effectively zero, then the retrieval can never move away from the initial guess.) We chose to implement a uniform tropospheric value in an attempt to avoid forcing the retrieval towards surface-maximum versus maximum-aloft profiles. The a priori profile is therefore different than the initial guess.

Our a priori uncertainties are high, and we might expect to encounter interesting cases (e.g., cases where the modelbased prior indicates the presence of a plume while there is actually clean air or vice versa) where our truth may be far from the a prior profiles. We have therefore used a relaxed retrieval constraint. The PAN constraint matrix used here is diagonal, with diagonal elements set to $(\ln (3.0))^{2}$ for all retrieval levels. The value chosen for the diagonal elements is somewhat arbitrary, but is large enough to allow for the retrieval to move far from the prior when necessary. For nadir retrievals, where vertical information is limited, it is common practice to introduce off-diagonal elements in the constraint matrix in order to avoid spurious oscillations in the retrieved profile. Due to the nature of the broad PAN spectral feature, or perhaps the relatively coarse spectral resolution of the PAN cross-section data used in the forward model, we found that the retrieval did not attempt to obtain better fits by introducing oscillations in the profile, and we did not find it necessary to introduce off-diagonal elements in the constraint matrix.

It is possible to construct a prior PAN covariance matrix (or matrices) from the GEOS-Chem profiles and use the inverse of this covariance as the constraint matrix. However, since it is difficult to know how well the model represents the real variability of PAN, and since models can have 

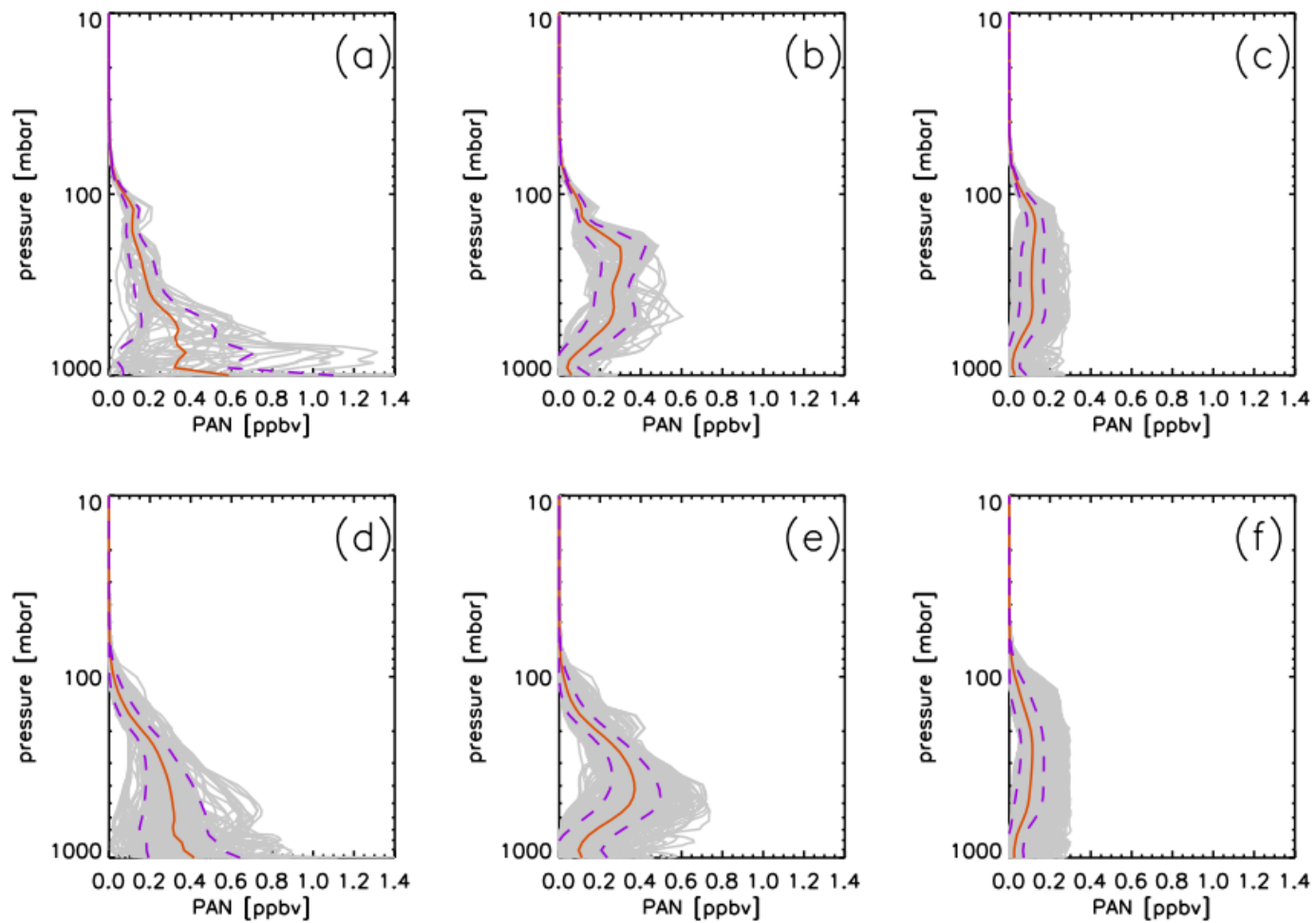

Figure 4. PAN profiles simulated by GEOS-Chem over the whole globe for July 2008, binned by type (in gray): (a) tropical profiles with a surface maximum; (b) tropical profiles with a maximum aloft; (c) tropical profiles with peak value $<0.3$ ppbv; (d) outside tropics, surface maximum; (e) outside tropics, maximum aloft; and (f) outside tropics, peak value $<0.3$ ppbv. The mean profiles for each category (shown in red) are used as a priori profiles in the TES PAN retrieval. Standard deviations about the mean (shown as purple dashed lines) are shown for information, but are not used in the construction of the retrieval constraints.

unphysical correlations that are not desirable for a constraint, e.g., between the troposphere and stratosphere (Kulawik et al., 2006a), we chose not to attempt this.

\subsection{Retrieval characteristics}

The PAN signals in the TES spectra are relatively weak compared to the noise level of the instrument (see Fig. 1). Therefore, the amount of information on PAN that can be retrieved from a single scan is somewhat limited. Figure 5 shows an example TES PAN retrieval for a measurement within a boreal fire plume (as determined by Alvarado et al., 2010, 2011), with associated averaging kernels. In this example, we see peak sensitivity to PAN at $300-400 \mathrm{hPa}$, with $\sim 1.0$ DOFS for the retrieval. While the pressure range of the peak sensitivity varies according to atmospheric and surface conditions, and the averaging kernels may peak much lower in the atmosphere for some cases where the peak in PAN concentration is near the surface, we find that the shape of the averaging kernels shown here is representative of the majority of TES PAN retrievals. In general, the number of DOFS is less than 1.0. Therefore, the TES PAN retrievals cannot provide information about the vertical structure of the PAN profile.

\subsection{Insight from simulated retrievals}

In order to evaluate the performance of the retrieval algorithm, we performed a set of retrievals from simulated radiances for one TES global survey from July 2008 (2786 observations). The "true" PAN profiles for these simulations were from GEOS-Chem simulations for the same month. Other atmospheric and surface parameters (temperature, traces gases, cloud optical depth, cloud top height, surface temperature and surface emissivity) for the simulations were taken from the version 5 TES level 2 products. Atmospheric and surface state information were used as input to the TES forward model in order to simulate top-of-atmosphere radiances and random noise based on TES instrument noise characteristics was added to the calculated radiances. We also simulated radiances for the same set of profiles, but with zero PAN. We calculated the PAN signal in each case by subtracting the "ero-PAN" spectrum from the "with-PAN" spectrum for each case.

We then calculated a signal-to-noise (SNR) value for each case, using the difference between the "with-PAN" $\left(\mathbf{L}_{\text {PAN }}\right)$ and the "zero-PAN" $\left(\mathbf{L}_{\text {NO_PAN }}\right)$ radiances and the TES noise for the PAN microwindows.

$\mathrm{SNR}=\left(\mathbf{L}_{\text {PAN }}-\mathbf{L}_{\text {NO_PAN }}\right)^{\mathbf{T}} \mathbf{S}_{n}^{-1}\left(\mathbf{L}_{\text {PAN }}-\mathbf{L}_{\text {NO_PAN }}\right)$ 
Table 2. Sources of uncertainty in TES PAN retrievals.

\begin{tabular}{|c|c|c|c|c|}
\hline \multirow[t]{2}{*}{ Index } & \multirow[t]{2}{*}{ Uncertainty } & \multirow[t]{2}{*}{ Nature } & \multicolumn{2}{|c|}{$\begin{array}{l}\text { Est. magnitude for profile with } 0.5 \mathrm{ppbv} \\
\text { PAN in the mid-troposphere }\end{array}$} \\
\hline & & & [ppbv] & {$[\%]$} \\
\hline 1 & Instrument noise & Random & 0.15 & $30 \%$ \\
\hline 2 & $\begin{array}{l}\text { Bias from } \\
\text { a priori }\end{array}$ & Systematic & $\begin{array}{l}\text { Depends on } \\
\text { a priori }\end{array}$ & - \\
\hline 3 & $\begin{array}{l}\text { Absolute instrument } \\
\text { calibration }\end{array}$ & Systematic & $\begin{array}{l}\text { Assumed } \\
\text { negligible }\end{array}$ & - \\
\hline 4 & Spectroscopic uncertainty & Systematic & 0.04 & $8 \%$ \\
\hline 5 & $\mathrm{H}_{2} \mathrm{O}$ & Pseudorandom & 0.1 & $20 \%$ \\
\hline 6 & $\mathrm{O}_{3}$ & Pseudorandom & 0.1 & $20 \%$ \\
\hline 7 & $\mathrm{~N}_{2} \mathrm{O}$ & Pseudorandom & 0.05 & $10 \%$ \\
\hline 8 & Surface temperature & Pseudorandom & 0.02 & $4 \%$ \\
\hline 9 & CFC-12 & Systematic & +0.08 or less & $+16 \%$ or less \\
\hline 10 & Emissivity (snow/ice) & Systematic & +0.1 or less & $+20 \%$ or less \\
\hline \multirow[t]{2}{*}{11} & Emissivity (silicate) & Systematic & -0.1 or less & $-20 \%$ or less \\
\hline & Aggregate of $1-8$ & & 0.22 & $43 \%$ \\
\hline
\end{tabular}

The GEOS-Chem fields used here for truth were the same set used to generate the prior. Therefore, in this simulation environment, the a priori state vector represents (as it should) our knowledge of a mean state.

Figure 6a shows a two-dimensional histogram of the SNR against the peak PAN concentration in the true profiles. (No retrieval is involved in the generation of this panel - only profile input and simulated radiances.) Of the 2786 cases, 600 show SNR $>1.0$. Since PAN is a relatively weak signal in TES spectra, we expected that we would only detect PAN in cases with low cloud optical depth (Alvarado et al., 2011). We find from these simulations that, with a cloud optical depth threshold of 0.5 , we retain 1709 of the original 2786 cases, and of those, 538 show SNR $>1.0$. This provides a rough indication that TES can likely observe elevated PAN for cases where the cloud optical depth is less than 0.5. This cloud optical depth threshold is approximate. If the PAN VMR were extremely high, a cloud optical depth greater than 0.5 would not necessarily prevent detection of the signal.

From Fig. 6a, on the lower-PAN edge of the histogram, we also see that a SNR value of 1.0 corresponds very roughly to a "maximum PAN" value of 0.2 ppbv. From this, we infer an approximate detection limit of $0.2 \mathrm{ppbv}$.

We performed PAN retrievals from the "with-PAN" simulated radiances. For this set of retrievals, the surface and atmospheric state were known perfectly. This is significantly less complicated than the situation when performing retrievals from real data, where there is inherent uncertainty associated with the additional surface and atmospheric parameters, even for those that have been retrieved in previous steps of the algorithm. These retrievals from simulations can provide insight into the limitations of the retrieval under idealized conditions.

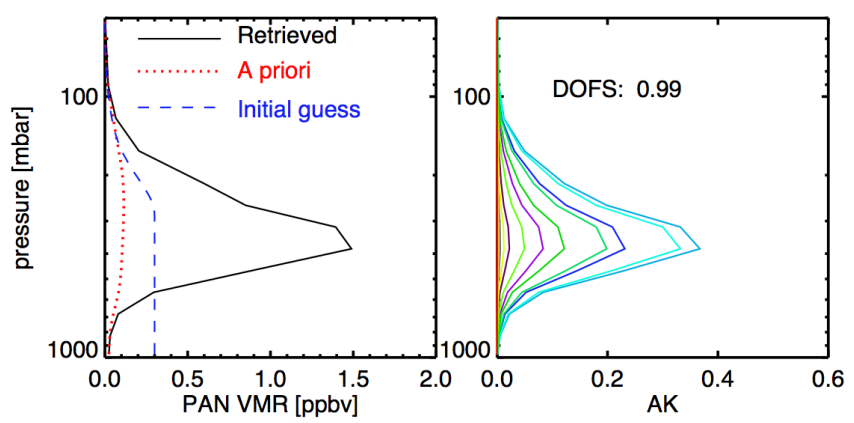

Figure 5. Left: example TES PAN retrieval for a measurement within a boreal fire plume. Right: averaging kernels for this example.

The limit of detection for the TES PAN retrievals is key to the determination of how the product can be used for science. We can think of the limit of detection as the atmospheric PAN concentration needed for the retrieval to return a value that has a significant contribution from the measurement, rather than just the a priori. Figure $6 \mathrm{~b}$ shows a two-dimensional histogram of the DOFS against the maximum PAN VMR in the true profiles. In general, we see that the DOFS is larger for cases with greater PAN VMRs. We also see that there is a limit of 1 DOFS in the PAN retrieval. If we set a threshold of DOFS $>0.6$ in order to distinguish cases where we expect to get a meaningful PAN retrieval, then we would also infer a detection limit in the region of $0.2 \mathrm{ppbv}$, roughly consistent with $\mathrm{SNR}=1.0$. 

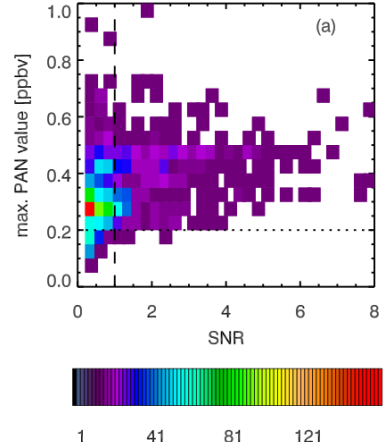

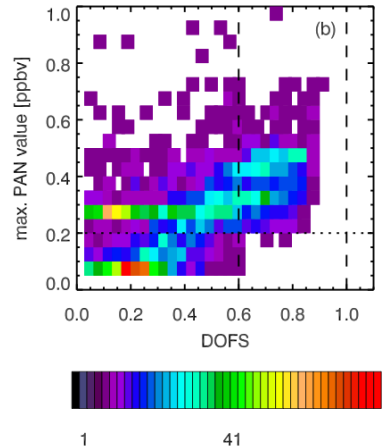

41

Figure 6. Results from retrieval simulations. (a) Two-dimensional histogram of signal to noise (SNR) against peak PAN VMR. (b) Two-dimensional histogram of DOFS against peak PAN VMR. Color bars show the number of points that fall in each histogram bin.

\subsection{Error estimates}

Sources of uncertainty considered here are listed in Table 2 and discussed in more detail below. These sources of uncertainty can be broadly divided into those that vary randomly from one measurement to the next, those that are systematic (e.g., spectroscopic uncertainty) and those that are "pseudorandom" (such as water vapor uncertainty). Those in the pseudorandom category may have a systematic component, but are still variable from one profile to the next.

In the simulated data set described in Sect. 3.5, we assume perfect knowledge of everything except the PAN values. This data set therefore provides the means to evaluate the impact of instrument noise on the retrieval for the case where all other error sources listed in Table 2 are equal to zero. Figure 7 shows the differences between the true and retrieved profiles as function of altitude, as well as the difference between true and retrieved values as a function of the true value. The difference between true and retrieved values is calculated as

$\Delta \boldsymbol{x}=\hat{\boldsymbol{x}}-\left(\boldsymbol{x}_{\mathrm{a}}+\mathbf{A}\left(\boldsymbol{x}_{\text {true }}-\boldsymbol{x}_{\mathrm{a}}\right)\right)$,

where $\hat{\boldsymbol{x}}$ is the retrieved state, $\mathbf{A}$ is the averaging kernel matrix, $\boldsymbol{x}_{\text {true }}$ is the true state and $\boldsymbol{x}_{\mathrm{a}}$ is the a priori state.

This figure only shows points for which the sum of the row of the averaging kernel is greater than 0.5. For cases with reasonable sensitivity, we see that the root-mean-square (rms) differences between the true and retrieved values are less than $0.1 \mathrm{ppbv}$ throughout the profile. We see that the rms difference between the true and retrieved states is less than the rms difference between the true and prior states for all altitudes, showing that the retrievals have skill. The retrievals appear to show greatest skill between $\sim 400$ and $800 \mathrm{hPa}$.

There is some uncertainty associated with the absolute radiance calibration of the TES instrument. Previous work (Connor et al., 2011; Shephard et al., 2008a) has also shown some systematic offsets between TES filters, on the order of tenths of a kelvin. However, our retrieval strategy should
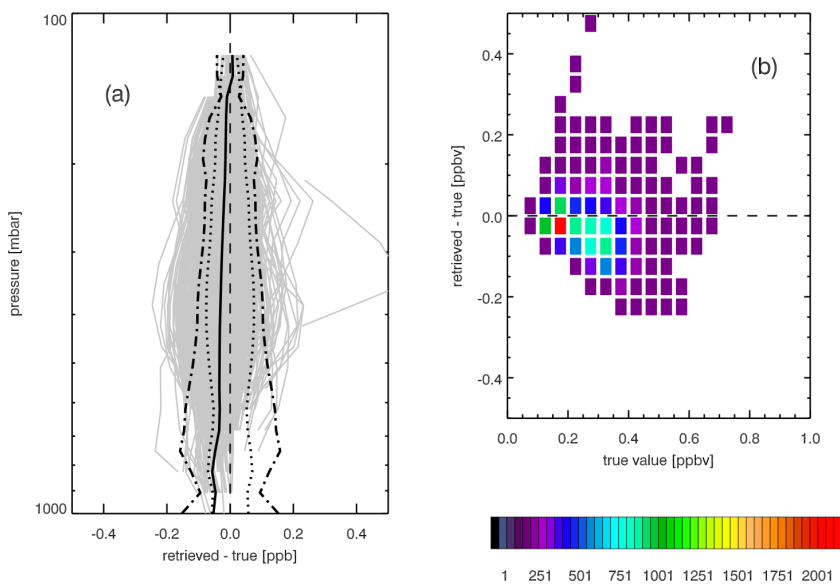

Figure 7. (a) Differences between retrieved and true PAN profiles for the simulated data set (after application of the averaging kernel and prior to the true profiles). The solid line shows the mean difference. Dotted and dot-dashed lines show the rms difference for (retrieved-true) and (prior-true), respectively. (b) Two-dimensional histogram of differences between the retrieved and true PAN values as a function of the true values. Plots show only profiles for which the maximum value in the true profile was greater than 0.2 and only points where the sum of the row of the averaging kernel is greater than 0.5 are shown. The color bar for (b) shows the number of points in each histogram bin.

mitigate the impact of this uncertainty in the PAN retrieval. (We re-retrieve cloud and surface emissivity before the PAN step in order to set a baseline against which the PAN signal can be assessed.) Connor er al. (2011) showed that the TES radiances exhibit excellent stability between 2005 and 2009. Subsequent work (T. Connor, personal communication, 2012) indicates that the radiances remained stable between 2010 and 2012. Therefore, drift in the radiance calibration in time should not be a concern for use of the TES PAN retrievals for assessing long-term variations such as interannual variability.

In the TES operational algorithm, trace gas retrievals are routinely performed in the presence of clouds. The clouds are implemented in the forward model as a single-layer Gaussian vertical profile parameterized by a cloud height and a set of frequency-dependent effective (non-scattering) optical depths (Kulawik et al., 2006b). Cloud optical depths are not expected to show spectral structure within the $\sim 40 \mathrm{~cm}^{-1}$ range of the PAN band used in this work.

If the surface emissivity and the cloud optical depth can be assumed to vary linearly with wave number across the $\sim 40 \mathrm{~cm}^{-1}$ wide PAN spectral region, we can assume that the impact of uncertainties in these quantities is also minimized by our choice of retrieval strategy. Over much of the Earth's surface, the assumption of linear variation in emissivity between 1140 and $1180 \mathrm{~cm}^{-1}$ is reasonable. However, this assumption is problematic over bare rocky or sandy surfaces, due to the silicate feature centered around 

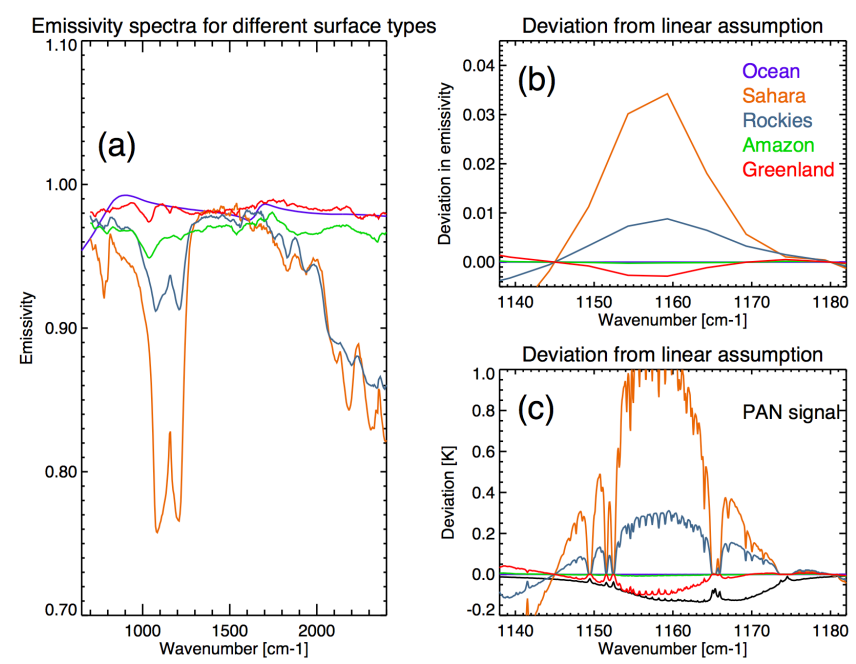

Figure 8. (a) Emissivity spectra for different surface types, taken from the UW/CIMSS HSR emissivity database. (b) Deviation of the emissivity spectra from a linear extrapolation between 1145 and $1180 \mathrm{~cm}^{-1}$. (c) Error in clear-sky brightness temperature resulting from the deviation of emissivity from the linear assumption. The black line in (c) represents the PAN signal associated with the July extratropical "maximum-aloft" profile shown in Fig. 4e and is shown for the purpose of illustrating the spectral shape of the PAN feature relative to the spectral shape of the signal associated with deviation from linear surface emissivity.

$1160 \mathrm{~cm}^{-1}$. Figure 8a shows emissivity spectra from the University of Wisconsin Cooperative Institute for Meteorological and Satellite Studies (UW/CIMSS) High Spectral Resolution (HSR) emissivity database (Borbas et al., 2007). A strong surface silicate feature will generally lead to a high $\chi_{\text {measurement }}^{2}$ value (Sect. 3.2), and so retrievals are generally not attempted for such cases. If the retrieval were to be attempted, the silicate feature would likely result in an underestimate of PAN (Fig. 8b). Spectral variation in the emissivity over snow or icy surfaces (see, for example, the "Greenland" plots in Fig. 8) leads to an error in the opposite sense from the silicate feature. However, since the shape of the deviation from linear emissivity does not match the shape of the PAN feature, any significant deviation from the linear emissivity will tend to result in high $\chi_{\text {measurement }}^{2}$ values, which either means that the retrieval is not attempted in the first place or that it will be rejected according to a final $\chi_{\text {measurement }}^{2}$ quality flag. (Retrievals where the final is greater than 1.5 are flagged as "bad"). Evidence suggests that cases where a nonlinear emissivity component produces a modeled radiance error that is equivalent in magnitude to a $\sim 0.1 \mathrm{ppbv}$ change in PAN would not pass quality control. We acknowledge that the variation in snow and sea-ice emissivity spectra is relatively large (Borbas and Ruston, 2010) and that it is not completely outside the realm of possibility that surfaces could exist for which the shape of the deviation from linear emissivity is a good match for the shape of the PAN signal. We will provide an upper bound of $+0.1 \mathrm{ppbv}$ "emissivity bias" for snow/ice surfaces and an equivalent bound of $-0.1 \mathrm{ppbv}$ emissivity bias for rocky surfaces.

Systematic errors in the PAN cross-section data used as input to the forward model would also result in systematic errors in the PAN retrieval. An error in the integrated band intensity of the PAN cross section would be expected to translate (roughly) into the same percentage error in the retrieved PAN VMR. Here, we used PAN cross sections from the HITRAN 2008 compilation (Rothman et al., 2009), which were in turn taken from the work of Allen et al. (2005a, b). These measurements were made at three temperatures in order to capture the temperature dependence of the cross section, but no measurements were recorded at temperatures below $250 \mathrm{~K}$. Allen et al. (2005a) cite uncertainties in the integrated band intensity of around $5 \%$ for the band used here, but this does not include the extrapolation error below $250 \mathrm{~K}$. Following the logic of Tereszchuk et al. (2013), we assume a value of $\sim 8 \%$ for the spectroscopic error.

Interfering species (see Fig. 1) are another potential source of uncertainty in the PAN retrievals. For the TES PAN retrievals, $\mathrm{H}_{2} \mathrm{O}$ is the dominant interfering species in the spectral range used. $\mathrm{H}_{2} \mathrm{O}$ is highly variable in space and time. The impact of $\mathrm{H}_{2} \mathrm{O}$ uncertainties is mitigated by our choice of microwindows and by the strategy of retrieving $\mathrm{H}_{2} \mathrm{O}$ in a previous step. Validation of previous versions of the TES $\mathrm{H}_{2} \mathrm{O}$ product indicate rms agreement of $25-45 \%$ with in situ validation data (Shepard et al., 2008b). Using the simulated data set described in Sect. 3.5, we performed an additional set of retrievals where we scaled the $\mathrm{H}_{2} \mathrm{O}$ in the initial guess atmospheric state for the PAN retrievals by random scaling factors with a standard deviation of $45 \%$. We found that the rms difference in the retrieved PAN between the perturbed $\mathrm{H}_{2} \mathrm{O}$ set and the reference data set was less than $0.1 \mathrm{ppbv}$, although we do find that there are isolated cases where an underestimate in the $\mathrm{H}_{2} \mathrm{O}$ can lead to spuriously high retrieved PAN values. For this reason, we require a good quality flag from the TES $\mathrm{H}_{2} \mathrm{O}$ retrieval for any given measurement before attempting a PAN retrieval.

Both $\mathrm{O}_{3}$ and $\mathrm{N}_{2} \mathrm{O}$ have relatively strong features in the spectral windows that we are using, but neither of these molecules shows a smooth variation that would be confused with a PAN signature. For $\mathrm{O}_{3}$, we assume a $40 \%$ rms uncertainty (based on TES $\mathrm{O}_{3}$ validation against ozonesondes at mid-latitudes - see Nassar et al., 2008). We find that this rms ozone uncertainty results in a $\sim 0.1 \mathrm{ppbv}$ rms uncertainty in the PAN retrievals. For $\mathrm{N}_{2} \mathrm{O}$, we assume a $2 \%$ rms uncertainty (based on global variability in tropospheric $\mathrm{N}_{2} \mathrm{O}$ VMR, as observed from global aircraft measurements of $\mathrm{N}_{2} \mathrm{O}$ (Wofsy et al., 2011). We find that this rms $\mathrm{N}_{2} \mathrm{O}$ uncertainty results in a $\sim 0.05$ ppbv rms uncertainty in the PAN retrievals. We do require that the $\mathrm{O}_{3}$ and $\mathrm{N}_{2} \mathrm{O}$ retrieved in previous retrieval steps pass basic quality flags before a PAN retrieval is attempted. However, significant errors in these molecules would result in a high initial $\chi_{\text {measurement }}^{2}$ value 


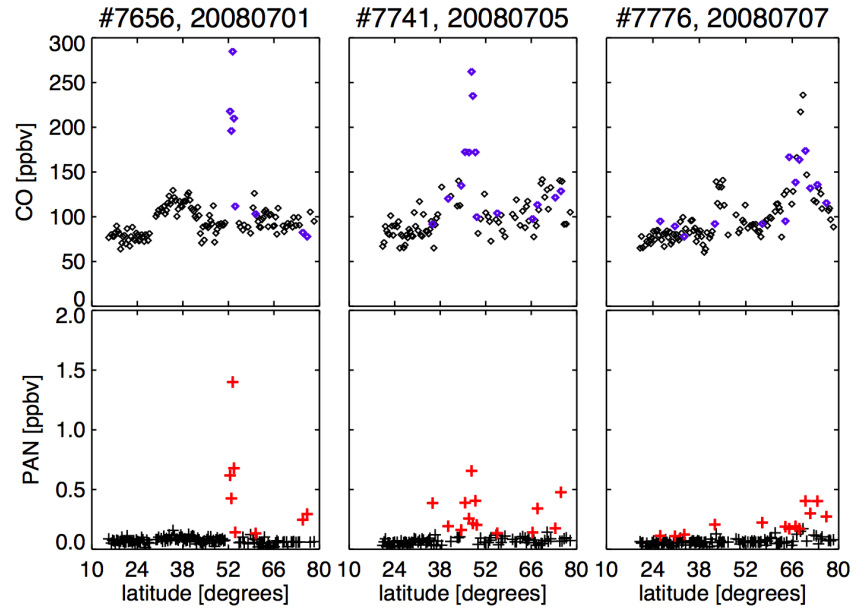

Figure 9. Examples of elevated $\mathrm{CO}$ and PAN in boreal burning plumes (previously identified by Alvarado et al., 2010) seen in TES special observations made during the July 2008 phase of the ARCTAS campaign. Colored points show the cases where the DOFS was greater than 0.6 for the PAN retrieval.

(Sect. 3.2), which would likely mean that a PAN retrieval would not be attempted in any case.

CFC-12 shows a smooth variation in the PAN spectral region. CFC-12 is extremely well mixed. Long-term, globally distributed surface measurements from the NOAA Earth Science Research Laboratory (ESRL) Global Monitoring Division (GMD) indicate that differences between measurements of CFC-12 in different parts of the globe are less than $3 \%$. There is a decrease of $\sim 8 \%$ in tropospheric values between 2005 and 2015. In the current TES climatology, we use a CFC-12 profile that is constant with time. TES climatology values for the current algorithm, based on 2004 values, are on the high side. If the true CFC-12 were $10 \%$ lower than the assumed CFC-12 (a pessimistic bias estimate), this would lead to an overestimate of mid-tropospheric PAN by $+0.08 \mathrm{ppbv}$. This error could be reduced by implementing a time-varying CFC-12 climatology. We assume that the error associated with other CFCs and HFCs with spectral features in this region is negligible compared with the other error sources.

Uncertainties in the surface temperature could also affect the PAN retrievals. Using the simulations, we find that an rms surface temperature uncertainty of $1 \mathrm{~K}$ leads to an rms error of $\sim 0.05 \mathrm{ppbv}$ in the mid-tropospheric PAN. Uncertainties in the temperature profile are another potential source of uncertainty in the PAN retrievals. Uncertainties in the TES temperature retrievals are on the order of a few kelvin. Here, we assume that the uncertainties associated with the PAN cross sections are significantly larger than the uncertainty associated with the retrieved temperature profile.

\section{Example retrieval results: Boreal burning plumes and Pacific Transport}

Figure 9 shows examples of elevated PAN and $\mathrm{CO}$ seen in boreal burning plumes during the July 2008 phase of the Arctic Research of the Composition of the Troposphere from Aircraft and Satellites (ARCTAS) campaign. The examples shown had been previously identified by Alvarado et al. (2010) as observations of burning plumes. We see sharp spatial gradients between PAN inside and outside of the plume. Since these TES observations are not colocated with aircraft observations, it was not possible to validate the absolute values. However, the TES-retrieved PAN values seem reasonable, given the range of PAN values measured by aircraft during the campaign (Alvarado et al., 2010; Roberts et al., 2009). The colored values correspond to cases where the DOFS for the PAN retrieval is greater than 0.6. This threshold was chosen to be roughly consistent with SNR $>1$ in the simulated results shown in Fig. 6.

These plume examples demonstrate that it is possible for adjacent TES pixels to show sharply different PAN concentrations. In general, the TES measurements sampled along the orbit track are relatively sparse. While special observations allow for closer spacing of observations along the orbit track, cross-track sampling is not available from TES. Validation of the TES PAN product against in situ data will require good spatial and temporal coincidences between TES and in situ data, for cases where elevated PAN is observed. Ideally, validation of the TES PAN retrievals would involve tightly colocated aircraft profiles, capturing plumes and covering the range of altitudes over which TES is sensitive. To date, this type of "true" validation data has not been available, although certain campaign measurements may still offer information of interest. TES step-and-stare special observations were taken during ARCTAS in 2008 and during the "Quantifying the impact of BOReal forest fires on Tropospheric oxidants over the Atlantic using Aircraft and Satellites" (BORTAS) campaign (Palmer et al., 2013) in 2011. TES transect observations were taken during the Front Range Air Pollution and Photochemistry Experiment (FRAPPE https://www2.acd.ucar.edu/frappe) in 2014. Comparisons of the TES PAN product against these types of independent observations will be a subject of future work.

Figure 10 shows a map of TES observations of elevated PAN over eastern Asia, the Pacific Ocean and the western US for 1 month (April 2008) in springtime, the season when we expect to see a strong contribution of Asian transport to US air pollution and a month with seasonably extreme biomass burning in northern Eurasia (Warneke et al., 2009; Warneke et al., 2010), as discussed next. The figure shows cases where the DOFS for the PAN retrieval is greater than 0.6. TES detects elevated PAN in a non-negligible number of cases.

We see cases where the PAN values retrieved by TES are $>2$ ppbv. In situ aircraft observations of PAN conducted in spring 2008 conducted as part of the ARCPAC (Aerosol, 

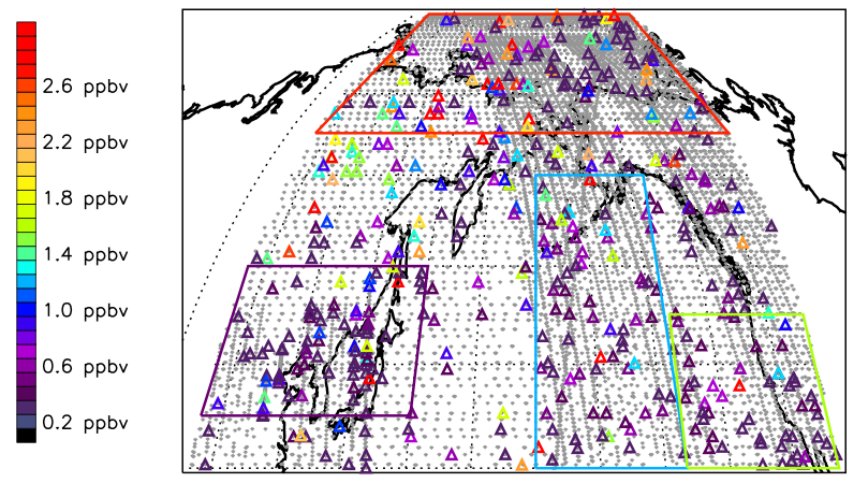

Figure 10. Gray points show all TES observations over the northern Pacific and surrounding land masses for April 2008. Colored triangles show points where elevated PAN was detected in the TES spectra with some confidence (DOFS $>0.6$ ). The VMR values represent the average over all points in the profile where the sum of the row of the averaging kernel is greater than 0.5. Colored latitude-longitude boxes highlight the regions associated with the histograms in Fig. 11.

Radiation and Cloud Processes affecting Arctic Climate) campaign also indicate elevated (1-3 ppbv) abundances of PAN associated with plumes of smoke originating in regions of intense biomass burning in Russia (Roberts et al., 2009). Screening out cases according to the TES $\mathrm{H}_{2} \mathrm{O}$ quality flag did remove a handful (3 out of 47) of cases of extremely high PAN (>2 ppbv), but not all of them. (Although the $\mathrm{H}_{2} \mathrm{O}$ quality screening did not dramatically change the number of cases of extremely high PAN, this test did screen out around $20 \%$ of PAN detections overall.) We note that the uncertainties on the TES PAN retrieval are relatively high (on the order of 30-50\%), but these estimates seem reasonable given the heavy impact of northern Eurasian biomass burning on the atmosphere at this time (Warneke et al., 2009, 2010). As discussed above, there could be additional uncertainty associated with PAN retrievals over snow or sea-ice surfaces, although it seems unlikely that this could account for the highly elevated PAN observed above the Arctic Circle. We also observe highly elevated PAN in the Arctic in July 2008 (not shown), when snow cover is far less extensive than in April, although the July data show fewer points at the extremely high end ( $>2$ ppbv) of the range.

Other aspects of the geographical distribution of elevated PAN values also appear as we might expect, with a higher density of elevated PAN detections and generally higher PAN values over the eastern Asian source region, and generally lower values and lower density of detections going out over the Pacific Ocean. The sporadic nature of extremely elevated PAN in biomass burning smoke is also reflected at high northern latitudes, extending from Russia across the northern Pacific. To explore this in a more quantitative way, we looked at the proportion of elevated PAN detections relative to the total number of TES observations in four latitude-longitude
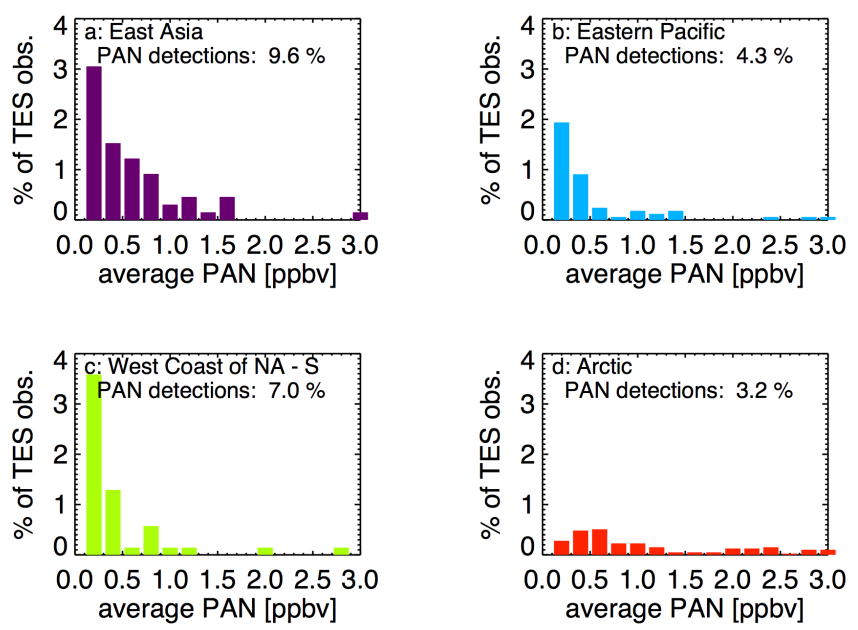

Figure 11. Incidences of elevated PAN as observed by TES during April 2008 in the latitude-longitude boxes shown in Fig. 10. VMR values represent the average for points in the profile where the sum of the row of the averaging kernel is greater than 0.5 .

boxes which separately represent the polluted Asian coast and immediate outflow region, the eastern Pacific and the Arctic (Fig. 11).

In the box over Asia, we see the highest occurrence of elevated PAN detections, with elevated PAN detected in 9.6\% of TES observations. The box over Asia also shows a higher occurrence of very high PAN values than the eastern Pacific. We see fewer PAN detections over the eastern Pacific (4.3\%). We also see a higher incidence of elevated PAN values $(7 \%)$ in the southern part of the west coast of North America. The retrieved values in this region are generally lower than those observed over Asia, and we speculate that this pattern is driven by North American pollution, where reactive nitrogen pollution advected off the coast is recirculated over the eastern Pacific. The Arctic region has a relatively high density of total TES observations. Although the incidence of elevated PAN values $(3.2 \%)$ is not as high as in the other highlighted regions, the Arctic shows the highest incidence of extremely high PAN values ( $>1.5 \mathrm{ppbv})$. We speculate that these high values are associated with springtime fires in northern Eurasia, but acknowledge that it is possible that they may reflect an overestimate driven by uncertainties in the snow and seaice emissivity spectra.

\section{Summary and conclusions}

We can detect elevated PAN in TES spectra. We show examples of boreal burning plumes during July 2008 and use initial data from April 2008. During April 2008, PAN was detected in $\sim 10 \%$ of TES observations over the Asian pollution source region, and elevated PAN over the North American Arctic associated with wildfires in Russia was also detected. The TES radiance data set provides global coverage 
over multiyear timescales, providing opportunities for investigations of tropospheric PAN on spatial and temporal scales that have not been possible with in situ measurements.

Results from simulated retrievals suggest that TES can detect PAN in profiles where the maximum value is around 200 pptv, although the presence of elevated PAN values in the atmosphere viewed by TES does not guarantee that TES can detect PAN. The detection of PAN in TES spectra is also subject to the atmospheric and surface conditions.

The uncertainty in TES PAN retrievals is on the order of $30-50 \%$. The error budget is largely dominated by the instrument noise. However, since PAN is highly spatially variable and TES is not capable of measuring "background" PAN levels, the TES PAN data set is not suitable for simple spatial averaging. We suggest that the utility of the TES PAN data set will lie in providing information on the frequency of incidence of elevated PAN on a global scale and on multiyear timescales.

The retrieval approach presented here will be implemented in the TES v07 algorithm. This approach could potentially be applied to other nadir infrared sounders, such as the Infrared Atmospheric Sounding Instrument (IASI), the Atmospheric InfraRed Sounding Instrument (AIRS) and the Cross-track Infrared Sounder (CrIS). These instruments have lower spectral resolution than TES, but significantly greater spatial coverage, providing an increased probability of observing highPAN plumes.

Acknowledgements. We would like to thank the two anonymous reviewers, whose constructive input led to marked improvements in the manuscript. This research was carried out at the Jet Propulsion Laboratory, California Institute of Technology, under a contract with the National Aeronautics and Space Administration. Reference herein to any specific commercial product, process or service by trade name, trademark, manufacturer or otherwise does not constitute or imply its endorsement by the United States Government or the Jet Propulsion Laboratory, California Institute of Technology.

Edited by: T. von Clarmann

\section{References}

Allen, G., Remedios, J. J., Newnham, D. A., Smith, K. M., and Monks, P. S.: Improved mid-infrared cross-sections for peroxyacetyl nitrate (PAN) vapour, Atmos. Chem. Phys., 5, 47-56, doi:10.5194/acp-5-47-2005, 2005a.

Allen, G., Remedios, J. J., and Smith, K. M.: Low temperature midinfrared cross-sections for peroxyacetyl nitrate (PAN) vapour, Atmos. Chem. Phys., 5, 3153-3158, doi:10.5194/acp-5-31532005, 2005.

Alvarado, M. J., Logan, J. A., Mao, J., Apel, E., Riemer, D., Blake, D., Cohen, R. C., Min, K.-E., Perring, A. E., Browne, E. C., Wooldridge, P. J., Diskin, G. S., Sachse, G. W., Fuelberg, H., Sessions, W. R., Harrigan, D. L., Huey, G., Liao, J., Case-Hanks, A., Jimenez, J. L., Cubison, M. J., Vay, S. A., Weinheimer, A. J., Knapp, D. J., Montzka, D. D., Flocke, F. M., Pollack, I.
B., Wennberg, P. O., Kurten, A., Crounse, J., Clair, J. M. St., Wisthaler, A., Mikoviny, T., Yantosca, R. M., Carouge, C. C., and Le Sager, P.: Nitrogen oxides and PAN in plumes from boreal fires during ARCTAS-B and their impact on ozone: an integrated analysis of aircraft and satellite observations, Atmos. Chem. Phys., 10, 9739-9760, doi:10.5194/acp-10-9739-2010, 2010.

Alvarado, M. J., Cady-Pereira, K. E., Xiao, Y., Millet, D. B., and Payne, V. H.: Emission Ratios for Ammonia and Formic Acid and Observations of Peroxy Acetyl Nitrate (PAN) and Ethylene in Biomass Burning Smoke as Seen by the Tropospheric Emission Spectrometer (TES), Atmosphere, 2, 633-654, 2011

Beer, R., Glavich, T. A., and Rider, D. M.: Tropospheric emission spectrometer for the Earth Observing System's Aura satellite, Appl. Optics 40, 2356-2367, 2001.

Borbas, E. E., Knuteson, R. O., Seemann, S. W., Weisz, E., Moy, L., and Huang, H.-L.: A high spectral resolution global land surface infrared emissivity database, Joint 2007 EUMETSAT Meteorological Satellite Conference and the 15th Satellite Meteorology \& Oceanography Conference of the American Meteorological Society, Amsterdam, the Netherlands, 24-28 September 2007

Borbas, E. E. and Ruston, B.: The RTTOV UWiremis IR land surface emissivity module. Mission, Report EUMETSAT NWPSAF-MO-VS-042, 2010.

Bowman, K. W., Rodgers, C. D., Sund-Kulawik, S., Worden, J., Sarkissian, E., Osterman, G., Steck, T., Luo, M., Eldering, A., Shephard, M. W., Worden, H., Clough, S. A., Brown, P. D., Rinsland, C. P., Lampel, M., Gunson, M., and Beer, R.: Tropospheric emission spectrometer: Retrieval method and error analysis, IEEE Geosci. Remote Sens., 44, 1297-1307, 2006.

Cady-Pereira, K. E., Shephard, M. W., Millet, D. B., Luo, M., Wells, K. C., Xiao, Y., Payne, V. H., and Worden, J.: Methanol from TES global observations: retrieval algorithm and seasonal and spatial variability, Atmos. Chem. Phys., 12, 8189-8203, doi:10.5194/acp-12-8189-2012, 2012.

Clarisse, L., R'Honi, Y., Coheur, P.-F., Hurtmans, D., and Clerbaux, C.: Thermal infrared nadir observations of 24 atmospheric gases, Geophys. Res. Lett, 38 , L10802, doi:10.1029/2011GL047271, 2011.

Clough, S. A., Shephard, M. W., Worden, J., Brown, P. D., Worden, H. M., Luo, M., Rodgers, C. D., Rinsland, C. P., Goldman, A., Brown, L., Kulawik, S. S., Eldering, A., Lampel, M. C., Osterman, G., Beer, R., Bowman, K., Cady-Pereira, K. E., and Mlawer, E. J.: Forward Model and Jacobians for Tropospheric Emission Spectrometer Retrievals, IEEE Trans. Geosci. Remote Sens., 44, 1308-1323, 2006.

Coheur, P.-F., Clarisse, L., Turquety, S., Hurtmans, D., and Clerbaux, C.: IASI measurements of reactive trace species in biomass burning plumes, Atmos. Chem. Phys., 9, 5655-5667, doi:10.5194/acp-9-5655-2009, 2009.

Connor, T. C., Shephard, M. W., Payne, V. H., Cady-Pereira, K. E., Kulawik, S. S., Luo, M., Osterman, G., and Lampel, M. Long-term stability of TES satellite radiance measurements, Atmos. Meas. Tech., 4, 1481-1490, doi:10.5194/amt-4-1481-2011, 2011.

Fischer, E. V., Jaffe, D. A., Reidmiller, D. R., and Jaegle, L.: Meteorological controls on observed peroxyacetyl nitrate at Mount Bachelor during the spring of 2008, J. Geophys. Res., 109, D18302, doi:10.1029/2009jd012776, 2010 
Fischer, E. V., Jaffe, D. A., and Weatherhead, E. C.: Free tropospheric peroxyacetyl nitrate (PAN) and ozone at Mount Bachelor: potential causes of variability and timescale for trend detection, Atmos. Chem. Phys., 11, 5641-5654, doi:10.5194/acp-115641-2011, 2011.

Fischer, E. V., Jacob, D. J., Yantosca, R. M., Sulprizio, M. P., Millet, D. B., Mao, J., Paulot, F., Singh, H. B., Roiger, A., Ries, L., Talbot, R.W., Dzepina, K., and Pandey Deolal, S.: Atmospheric peroxyacetyl nitrate (PAN): a global budget and source attribution, Atmos. Chem. Phys., 14, 2679-2698, doi:10.5194/acp-142679-2014, 2014.

Gaffney, J. S., Fajer, R., and Senum, G. I.: An improved procedure for high purity gaseous peroxyacetyl nitrate production: Use of heavy lipid solvents, Atmos. Envir., 18, 215-218, 1984

Hudman, R. C., Jacob, D. J., Cooper, O. R., Evans, M. J., Heald, C. L., pek, R. J., Fesenfeld, F., Flocke, F., Holloway, J., Huebler, G., Kita, K., Koike, M., Kondo, Y., Neuman, A., Nowak, J., Oltmans, S., Parrish, D., Roberts, J. M. and Ryersonm T.: Ozone production in transpacific Asian pollution plumes and implications for air quality in California, J. Geophys. Res., 109, DS23S10, doi:10.1029/2004JD004974, 2004

Jacob, D. J., Logan, J. A., and Murti, P. P.: Effect of rising Asian emissions on surface ozone in the United States, Geophys. Res. Lett., 26, 2175-2178, 1999.

Kotchenruther, R. A., Jaffe, D. A., and Jaegle, L.: Ozone photochemistry and the role of peroxyacetyl nitrate in the springtime northeastern Pacific troposphere: Results from the Photochemical Ozone Budget of the Eastern North Pacific (PHOEBEA) campaign, J. Geophys. Res., 106, 28731-728741, 2001a.

Kotchenruther, R. A., Jaffe, D. A., Beine, H. J., Anderson, T., Bottenheim, J. W., Harris, J., Blake, D., and Schmidt, R. W. H.: Observations of ozone and related species in the northeast $\mathrm{Pa}-$ cific during the PHOBEA campaigns: 2. Airborne observations, J. Geophys. Res., 106, 7463-7483, 2001b.

Kulawik, S. S., Osterman, G., Jones, D. B. A., and Bowman, K. W.: Calculation of altitude-dependent Tikhonov constraints for TES nadir retrievals, IEEE Trans. Geosci. Remote Sens., 44, 1334-1342, 2006a.

Kulawik, S. S., Worden, J., Eldering, A., Bowman, K., Gunson, M., Osterman, G. B., Zhang, L., Clough, S., Shephard, M. W., and Beer, R.: Implementation of cloud retrievals for Tropospheric Emission Spectrometer (TES) atmospheric retrievals: part 1. Description and characterization of errors on trace gas retrievals, J. Geophys. Res., 111, D24204, doi:10.1029/2005JD006733, 2006b.

Moore, D. P. and Remedios, J. J.: Seasonality of Peroxyacetyl nitrate (PAN) in the upper troposphere and lower stratosphere using the MIPAS-E instrument, Atmos. Chem. Phys., 10, 6117-6128 doi:10.5194/acp-10-6117-2010, 2010

Nassar, R., Logan, J. A., Worden, H. M., Megretskaia, I. A., Bowman, K. W., Osterman, G. B., Thompson, A. M., Tarasick, D. W., Austin, S., Claude, H., Dubey, M. K., Hocking, W. K., Johnson, B. J., Joseph, E., Merrill, J., Morris, G., Newchurch, M., Oltmans, S.J., Posny, F., Scmidlin, F. J., VOelmel, H., Whiteman, D. N., and Witte, J. C.: Validation of Tropospheric Emission Spectrometer (TES) nadir ozone profiles using ozonesonde measurements, J. Geophys. Res., 113, D15S17, doi:10.1029/2007JD008819, 2008
Nowak, J. B., Parrish, D. D., Newman, J. A., Holloway, J. S., Cooper, O. R., Ryerson, T. B., Nicks Jr., D. K., Flocke, F., Roberts, J. M., Atlas, E. L., de Gouw, J. A., Donnely, S. G., Dunlea, E., Hubler, G., Huey, L. G., Schauffler, S. M., Tanner, D. J., Warneke, C., and Fehsenfeld, F. C.: Gas-phase chemical characteristics of Asian emission plumes observed during ITCT 2K2 over the eastern North Pacific Ocean, J. Geophys. Res., 109, D23S19, doi:10.1029/2003JD004488, 2004.

Palmer, P. I., Parrington, M., Lee, J. D., Lewis, A. C., Rickard, A. R., Bernath, P. F., Duck, T. J., Waugh, D. L., Tarasick, D. W., Andrews, S., Aruffo, E., Bailey, L. J., Barrett, E., Bauguitte, S. J.-B., Curry, K. R., Di Carlo, P., Chisholm, L., Dan, L., Forster, G., Franklin, J. E., Gibson, M. D., Griffin, D., Helmig, D., Hopkins, J. R., Hopper, J. T., Jenkin, M. E., Kindred, D., Kliever, J., Le Breton, M., Matthiesen, S., Maurice, M., Moller, S., Moore, D. P., Oram, D. E., O'Shea, S. J., Owen, R. C., Pagniello, C. M. L. S., Pawson, S., Percival, C. J., Pierce, J. R., Punjabi, S., Purvis, R. M., Remedios, J. J., Rotermund, K. M., Sakamoto, K. M., da Silva, A. M., Strawbridge, K. B., Strong, K., Taylor, J., Trigwell, R., Tereszchuk, K. A., Walker, K. A., Weaver, D., Whaley, C., and Young, J. C.: Quantifying the impact of BOReal forest fires on Tropospheric oxidants over the Atlantic using Aircraft and Satellites (BORTAS) experiment: design, execution and science overview, Atmos. Chem. Phys., 13, 6239-6261, doi:10.5194/acp-13-6239-2013, 2013.

Payne, V. H., Clough, S. A., Shephard, M. W., Nassar, R., and Logan, J. A.: Information-centered representation of retrievals with limited degrees of freedom for signal: Application to methane from the Tropospheric Emission Spectrometer, J. Geophys. Res., 114, D10307, doi:10.1029/2008JD010155, 2009.

Ridley, B. A., Shetter, J. D., Gandrud, B. W., Salas, L. J., Singh, H. B., Carroll, M. A., Hubler, G., Albritton, D. L., Hastie, D. R., Schiff, H. I., Mackay, G. I., Karechi, D. R., Davis, D. D., Bradshaw, J. D., Rodgers, M. O., Sandholm, S. T., Torres, A. L., Conden, E. P., Gregory, G. L., and Beck, S. M.: Ratios of peroxyacetyl nitrate to active nitrogen observed during aircraft flights over the Eastern Pacific Oceans and continental United States, J. Geophys. Res., 95, 10179-10192, 1990.

Roberts, J. M., Flocke, F., Chen, G., De Gouw, J. A., Holloway, J. S., Hubler, G., Neuman, J. A., Nicks Jr., D. K., Nowak, J. B., Parrish, D., Ryerson, T. B., Sueper, D. T., Warnecke, C., and Fehsenfeld, F. C.: Measurement of peroxycarboxylic nitric anhydrides (PANs) during the ITCT 2K2 aircraft intensive experiment, J. Geophys. Res., 109, D23S21, doi:10.1029/2004JD004960, 2004.

Roberts, J. R., Neuman, J., Nowak, J. B., Ryerson, T. B., Peischl, J. W., Holloway, J., Warneke, C., and de Gouw, J. A.: Measurements of Acylperoxynitrates (PANs) in Biomass Burning Plumes over the Arctic in Spring 2008, American Geophysical Union, Fall Meeting 2009, 2009.

Rodgers, C. D.: Inverse methods for atmospheric Sounding: Theory and Practice, World Sci., Hackensack, N. J., 2000. Rothman, L. S., Gordon, I. E., Barbe, A., Benner, C. D., Bernath, P. F., Birk, M., Boudon, V., Brown, L. R., Campargue, A., Champion, J.-P., Chance, K., Coudert, L. H., Dana, V., Devi, V. M., Fally, S.,Flaud, J.-M., Gamache, R. R., Goldman, A., Jaquemart, D., Kleiner, I., Lacome, N., Lafferty, W. J., Mandin, J.-Y., Massie, S. T., Mikhailenko, S. N., Miller, C. E., Moazzen-Ahmadi, N., Naumenko, O. V., Nitikin, A. V., Orpahl, J., Perevalov, V. I., Perrin, A., Predoi-Cross, A., Rinsland, C. P., Rotget, M., Simeck- 
ova, M., Smith, M. A. H., Sung, K., Tashkun, S. A., Tennyson, J., Toth, R. A., Vandaele, A. C., and Vaner Auwera, J.: The HITRAN 2008 molecular spectroscopic database, J. Quant. Spectroc. Radiat. Transfer, 110, 533-572, 2009.

Seemann, S. W., Borbas, E. E., Knuteson, R. O., Stephenson, G. R., and Huang, H.-L.: Development of a Global Infrared Land Surface Emissivity Database for Application to Clear Sky Sounding Retrievals from Multi-spectral Satellite Radiance Measurements.J. Appl. Meteor. Climatol., 47, 108-123, 2008.

Shephard, M. W., Worden, H. M., Cady-Pereira, K. E., Lampel, M., Luo, M., Bowman, K. W., Sarkissian, E., Beer, R., Rider, D. M., Tobin, D. C., Revercomb, H. E., Fisher, B. M., Tremblay, D., Clough, S. A., Osterman, G. B., and Gunson, M.: Tropospheric Emission Spectrometer Nadir Spectral Radiance Comparisons, J. Geophys. Res., 113, D15S05, doi:10.1029/2007JD008856, 2008a

Shephard, M. W., Herman, R. L., Fisher, B. M., Cady-Pereira, K. E., Clough, S. A., Payne, V. H., Whiteman, D. N., Comer, J. P., Voemel, H., Miloshevich, L. M., Forno, R., Adam, M., Osterman, G. B., Eldering, A., Worden, J. R., Brown, L. B., Worden, H. M., Kulawik, S. S., Rider, D. M., Goldman, A., Beer, R., Bowman, K. W., Rodgers, C. D., Luo, M., Rinsland, C. P., Lampel, M., and Gunson, M. R.: Comparisons of Tropospheric Emission Spectrometer nadir water vapor retrievals with in situ measurements, J. Geophys. Res., 113, D1516, doi:10.1029/2007JD008822, 2008b.

Singh, H. B. and Hanst, P. L.: Peroxyacetyl nitrate (PAN) in the unpolluted atmosphere: an important reservoir for nitrogen oxides, Geophys. Res. Lett., 8, 941-944, doi:10.1029/GL008i008p00941, 1981

Singh, H. B. and Salas, L. J.: Global distribution of peroxyacetyl nitrate, Nature, 321, 588-591, 1986.

Singh, H. B.: Reactive nitrogen in the tropospher: chemistry and transport of $\mathrm{NO}_{\mathrm{x}}$ and PAN, Environ. Sci. Technol., 21, 320-327, 1987

Singh, H. B., Condon, E., Vedder, J., O’Hara, D., Ridley, B. A., Gandrud, B. W., Shetter, J. D., Salas, L. J., Huebert, B. J., Hubler, G., Carroll, M. A., Albritton, D. L., Davis, D. D., Bradshaw, J. D., Sandholm, S. T., Rodgers, M. O., Beck, S. M., Gregory, G. L., and LeBel, P. J.: Peroxyacetyl nitrate measurements during CITE 2: Atmospheric distribution and precursor relationships, J. Geophys. Res., 95, 10163-10178, 1990.

Singh, H. B., Viezee, W., Chen, Y., Thakur, A. N., Kondo, Y., Talbot, R. W., Gregory, G. L., Sachse, G. W., Blake, D. R., Bradshaw, J. D., Wang, L., and Jacob, D. J.: Latitudinal distribution of reactive nitrogen in the free troposphere over the Pacific Ocean in late winter/early spring, J. Geophys. Res., 103, 28237-28246, 1998.

Singh, H. B., Brune, W. H., Crawford, J. H., Flocke, F., and Jacob, D. J.: Chemistry and transport of pollution over the Gulf of Mexico and the Pacific: spring 2006 INTEX-B campaign overview and first results, Atmos. Chem. Phys., 9, 2301-2318, doi:10.5194/acp-9-2301-2009, 2009.
Tereszchuk, K. A., Moore, D. P., Harrison, J. J., Boone, C. D., Park, M., Remedios, J. J., Randel, W. J., and Bernath, P. F.: Observations of peroxyacetyl nitrate (PAN) in the upper troposphere by the Atmospheric Chemistry Experiment-Fourier Transform Spectrometer (ACE-FTS), Atmos. Chem. Phys., 13, 5601-5613, doi:10.5194/acp-13-5601-2013, 2013.

Tsalkani, N. and Toupance, G.: Infrared absorptivities and integrated band intensities for gaseous peroxyacetyl nitrate (PAN), Atmos. Envir., 23, 1849-1854, 1989

Warneke, C., R. Bahreini, J. Brioude, C. A. Brock, J. A. de Gouw, D. W. Fahey, K. D. Froyd, J. S. Holloway, A. Middlebrook, L. Miller, S. Montzka, D. M. Murphy, J. Peischl, T. B. Ryerson, J. P. Schwarz, J. R. Spackman, and P. Veres: Biomass burning in Siberia and Kazakhstan as an important source for haze over the Alaskan Arctic in April 2008, Geophys. Res. Lett., 36, L02813, doi:10.1029/2008gl036194, 2009.

Warneke, C., Froyd, K. D., Brioude, J., Bahreini, R., Brock, C. A., Cozic, J., de Gouw, J. A., Fahey, D. W., Ferrare, R., Holloway, J. S., Middlebrook, A. M., Miller, L., Montzka, S., Schwarz, J. P., Sodemann, H., Spackman, J. R., and Stohl, A.: An important contribution to springtime Arctic aerosol from biomass burning in Russia, Geophys. Res. Lett., 37, L01801, doi:10.1029/2009gl041816, 2010.

Wiegele, A., Glatthor, N., Höpfner, M., Grabowski, U., Kellmann, S., Linden, A., Stiller, G., and von Clarmann, T.: Global distributions of $\mathrm{C}_{2} \mathrm{H}_{6}, \mathrm{C}_{2} \mathrm{H}_{2}, \mathrm{HCN}$, and PAN retrieved from MIPAS reduced spectral resolution measurements, Atmos. Meas. Tech., 5, 723-734, doi:10.5194/amt-5-723-2012, 2012.

Wofsy, S. C.: The HIPPO Science Team and Co-operating Modeling and Satellite Teams: HIAPER Pole-to-Pole Observations (HIPPO): fine-grained, global-scale measurements of climatically important atmospheric gases and aerosols, Phil. Trans. R. Soc. A, 369, 2073-2086, 2011.

Wolfe, G. M., Thornton, J. A., McNeill, V. F., Jaffe, D. A., Reidmiller, D., Chand, D., Smith, J., Swartzendruber, P., Flocke, F., and Zheng, W.: Influence of trans-Pacific pollution transport on acyl peroxy nitrate abundances and speciation at Mount Bachelor Observatory during INTEX-B, Atmos. Chem. Phys., 7, 5309-5325, doi:10.5194/acp-7-5309-2007, 2007.

Zhang, L., Jacob, D. J., Boersma, K. F., Jaffe, D. A., Olson, J. R., Bowman, K. W., Worden, J. R., Thompson, A. M., Avery, M. A., Cohen, R. C., Dibb, J. E., Flock, F. M., Fuelberg, H. E., Huey, L. G., McMillan, W. W., Singh, H. B., and Weinheimer, A. J.: Transpacific transport of ozone pollution and the effect of Asian emission increases on air quality in North America: An integrated analysis using satellite, aircraft, ozonesonde and surface observations, Atmos. Chem. Phys., 8, 6117-6136, 2008, http://www.atmos-chem-phys.net/8/6117/2008/. 